\title{
"O que se passa por aqui": cartografando processos da Oficina de Palavras em um Centro de Convivência
}

DOI: https://doi.org/10.5935/1984-9044.20200017

\author{
Luísa Milano Navarro ${ }^{12}$ - Universidade Estadual de Campinas (UNICAMP)
}

Resumo: Este artigo pretende apresentar e discutir o processo de construção do grupo "Oficina de Palavras", iniciado durante trabalho de campo do segundo ano de formação na Residência Multiprofissional de Saúde Mental da UNICAMP, realizado em um Centro de Convivência (Ceco). Para percorrer esse trajeto, serão utilizados pistas e recursos do Método da Cartografia, postulado por Deleuze e Guatari. Com uma revisita aos diários de campo da Oficina, registros afetivos e inquietações suscitadas por tais afetos, buscar-se-á compreender o que a produz e o que por ela é produzido, levantando reflexões acerca dos modos de subjetivação e produção de vida observados na prática, com base na interlocução do cuidado com a arte e a produção do comum. Veremos como a apropriação de um modo de expressão dominante (a escrita) por parte dos participantes da oficina propiciou o atravessamento da linha divisória que separa esses corpos da produção cultural. Existe um aumento da cidadania cultural, extremamente relevante no tocante à produção da vida e ampliação de suas possibilidades.

PALAVRAS-CHAVE: centro de convivência; cartografia; saúde mental.

\section{"What's going on here": cartography of theWords Workshop in a Community Center}

\begin{abstract}
This article intends to present and discuss the construction process of the group "Oficina de Palavras", started during fieldwork of the second year of training at the Multiprofessional Mental Health Residence at UNICAMP, held in a Community Center. To cover this path, clues and resources from the Cartography Method postulated by Deleuze and Guatarri, will be used. From a return visit to the group field diaries, affective records and concerns raised by such affections, one will seek to understand what produces the group and what is produced by it, raising reflections about the modes of subjectivities and production of life observed in practice, from the dialogue between care, art and production of the common.
\end{abstract}

\footnotetext{
${ }^{1}$ Artigo baseado no Trabalho de Conclusão de Curso da autora, sob orientação de Bruno Ferrari Emerich

2 ORCID: http://orcid.org/0000-0001-6082-7155
} 
"O QUE SE PASSA POR AQUI": CARTOGRAFANDO PROCESSOS DA OFICINA DE PALAVRAS EM UM

CENTRO DE CONVIVÊNCIA

We will see how the workshop participants' appropriation of a dominant mode of expression (writing) led to the crossing of the dividing line that separates these bodies from cultural production. There is an increase in cultural citizenship, which is extremely relevant to the production of life and the expansion of its possibilities.

KEY WORDS: community center; cartography; mental health.

\section{Introdução}

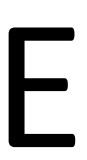

ste artigo intenta contar um processo. Trata-se do percurso de um projeto que posteriormente nomeou-se "Oficina de Palavras", dispositivo construído durante a experiência de campo na condição de psicóloga residente de Saúde Mental, em um Centro de Convivência localizado em Campinas/SP. O presente artigo propõese, portanto, a apresentar e descrever o processo de construção e encontros da Oficina, iniciada durante trabalho de campo do segundo ano de formação na Residência Multiprofissional de Saúde Mental da UNICAMP,

Para percorrer esse trajeto, serão utilizados pistas e recursos do Método da Cartografia, postulado por
Deleuze e Guatari (1995). Os autores apresentam a Cartografia como uma metodologia que se propõe a acompanhar processos. Trata-se, portanto, da investigação de um processo de produção.

Conforme aponta Rolnik (1989), o termo "cartografia", oriundo da geografia, traduz o método de desenhos criados em simultaneidade ao movimento de transformação da paisagem.

O que Deleuze e Guattari (1995) propõem em sua metodologia cartográfica aproxima-se da definição expressa na geografia, na medida em que "paisagens psicossociais também são cartografáveis" (Rolnik, 1989, p. 2), sendo a prática de um cartógrafo, inevitavelmente, relacionada aos meios 
"O QUE SE PASSA POR AQUI": CARTOGRAFANDO PROCESSOS DA OFICINA DE PALAVRAS EM UM CENTRO DE CONVIVÊNCIA

da formação dos desejos no campo social, independente de qual âmbito da vida social e da existência humana o cartógrafo ponha-se a acompanhar. Ao cartógrafo cabe a tarefa de "dar língua a afetos que pedem passagem" (Rolnik, 1989, p. 1).

Para Escóssia, Kastrup e Passos (2015), a cartografia não constitui uma metodologia a ser aplicada, mas sim experimentada, assumida como atitude sem, contudo, perder o rigor. Neste sentido, "a precisão não é tomada como exatidão, mas como compromisso e interesse, como implicação na realidade, como intervenção". (Escóssia et al., 2015, p. 11)

Para dar continuidade à desafiadora tarefa aqui proposta, faz-se pertinente uma compreensão mais detalhada acerca do funcionamento, objetivos e origem dos dispositivos denominados Centros de Convivência (Cecos). Em seguida, uma breve explanação acerca das particularidades desses serviços na RAPS ajudará a compreender o contexto em que se inserem e, enfim, o encontro com esse dispositivo e o construir diário da Oficina de Palavras.

\section{Os Centros de Convivência (Ceco)}

Tal qual grande parte dos serviços e práticas hoje instituídas como Políticas Públicas que compõem a Rede de Atenção Psicossocial (RAPS), os Ceco surgiram a partir de práticas exitosas e revolucionárias no campo do cuidado. As primeiras experiências aconteceram na cidade de São Paulo, no final da década de 1980. De acordo com Galletti (2004), os Ceco nascem com a proposta de constituir-se como espaços alternativos de convivência abertos a toda a população, com principal enfoque na inclusão das diferenças, tendo como público-alvo "os setores populares que tinham menores chances de vida - 'vida física' e 'vida psíquica' - cuja identidade é marcada pelo estigma que marginaliza e segrega"(Galetti, 2004, p. 53). 
A proposta dos CECOS consiste na busca por:

Inclusão, cuidado, pertencimento, grupalidade e descoberta de outras formas possíveis de expressão da vida. (...) Sua estratégia de ação está no ato de convidar, oferecer, compartilhar, proporcionar ao outro algo de bom a cada encontro, mediado pela convivência como promotora de cuidado (Aleixo, 2013, p. 92).

O documento de Normatização das Ações nos Centros de Convivência e Cooperativas Municipais, elaborado pela Prefeitura Municipal de São Paulo (1992), designa a equipe dos Ceco de “interventora-facilitadora" da convivência. Na portaria Ministerial $\mathrm{n}$. 3.088 (2011), que oficializa a Rede de Atenção Psicossocial (RAPS), os Ceco são apontados como equipamentos da Atenção Básica nas ações de inclusão social e definem-se como locais de cuidado, destinados à população em geral, que ofertam possibilidades de sociabilidade, intervenção na cultura e na cidade.
Para realizar o que propõe, o Ceco tem no cerne de suas estratégias de ação a realização de práticas coletivas que, segundo Aleixo (2013), viabilizam a produção de convivência social, funcionam através da oferta de oficinas, grupos e ações comunitárias, criando verdadeiros "espaços de produção" (p. 94). Na contramão do projeto neoliberal, os Centros de Convivência buscam a produção artesanal de novas formas de convívio e apropriação do espaço público (Galletti,2004).

O Centro de Convivência de que trata este artigo foi uma iniciativa de profissionais do Centro de Atenção Psicossocial (CAPS) da região Sul da cidade, em parceria com profissionais da Fundação Municipal para Educação Comunitária (FUMEC) (Ferigato, 2013).

Aleixo (2016) aponta que o espaço foi idealizado pelos trabalhadores como possibilidade de ampliação da socialização e circulação de seus frequentadores. No momento presente, conta com duas profissionais de ensino superior (Psicóloga e Terapeuta Ocupacional), uma gestora, uma 
"O QUE SE PASSA POR AQUI": CARTOGRAFANDO PROCESSOS DA OFICINA DE PALAVRAS EM UM CENTRO DE CONVIVÊNCIA

monitora e uma auxiliar de limpeza. Além destas, participam das ações e das atividades do serviço os estagiários e residentes de Psicologia e Terapia Ocupacional vinculados a diferentes Universidades.

Uma variada oferta de oficinas e atividades compõe o cotidiano do Ceco, que possibilitam a experimentação com o corpo, com a arte, além de passeios e parcerias com as mais diversas instituições e serviços, ampliando os espaços de circulação e atuação do Centro de Convivência no território. Esse território abrange a maior região sanitária da cidade, marcado por intensa desigualdade social entre os bairros que o compõe.

\section{Cartografando o processo}

"Sempre que o Cartógrafo entra em campo há processos em curso" (Barros e Kastrup, 2009, p. 56). Foi no "processo em curso" do Ceco, que iniciei meu segundo ano de práticas da Residência Multiprofissional de Saúde Mental. Um período que desafiou constantemente o tornar-me psicóloga no contexto das Políticas Públicas de Saúde Mental.

Sendo os Cecos dispositivos que se localizam na fronteira entre o campo da clínica e o campo social (Galletti, 2004), a ampliação do conceito mais formal de clínica produziu muitos estranhamentos e inquietações. As Oficinas, principais dispositivos implementados no Ceco, convocam para uma desestabilização dos núcleos profissionais e especialidades, ou seja, das funções pré-estabelecidas. A ampliação das formas de cuidado traz em sua radicalidade o redimensionamento dos lugares e papéis na construção do cuidado.

Portanto, "o embaralhamento dos papéis do 'terapeuta-oficineiro', da 'terapiaoficina' e do 'paciente-usuário' desenvolveu novos contornos para essas montagens clínicas, mistos de teorias e de práticas que as próprias experiências foram constelando" (Galletti, 2004 p. 59). 
As conversas, ações e atividades não envolvem atendimentos individuais, não são pautadas na intervenção medicamentosa, ou em diagnósticos psiquiátricos. A única agenda é aquela que oferta as oficinas semanais, em um espaço que pensa Projetos de Vida, ao invés de Projetos Terapêuticos. A clínica, nessa configuração, não objetiva remissão de sintomas; volta-se para a promoção de processos de vida e de criação, é uma clínica que se faz no território. (Lima, 2006). De Barros e Kastrup (2009), ao lançarem mão de conceitos da etnografia para abordar pistas e reflexões acerca do método cartográfico, apontam, na aproximação entre as duas ferramentas, que a pesquisa cartográfica requer do cartógrafo a inserção em um território inicialmente por ele não habitado. Valendo-se da "observação participante" etnográfica, o cartógrafo mantém-se em contato direto com as pessoas e o território existencial do campo em que se insere, na medida em que experimenta sempre algum grau de afastamento e estranhamento da vida ali percebida e sentida.
Tal qual uma aprendiz de etnógrafacartógrafa, iniciei o ano de residência no Ceco com ávida curiosidade. No espaço de convivência, entre atividades, durante grupos e oficinas, ouvi os frequentadores do Ceco contarem suas "histórias". Participando do grupo de Dança do Ventre, conheci um caderno do grupo, no qual as dançarinas escrevem suas impressões e sensações da oficina. Ao desbravar as pastas em que se registram as presenças e encontros das oficinas, encontrei um caderno intitulado "Ideias e Sentimentos do Mosaico". Durante uma tarde inteira, escrevi cartas com uma antiga frequentadora do Ceco e assídua aluna da FUMEC. Esses movimentos recordaram grande paixão e afinidade com a expressão e significação através da escrita.

Essas e outras vivências de campo conduziram-me a uma espécie de detecção dos signos e forças que ali circulavam, à percepção de "forças do processo em curso", tal qual postulado por Kastrup (2007, p. 15). A tentativa de acolher aquilo que surgiu da espontaneidade dos encontros e a atenção às experiências, que não 
necessariamente tinham um sentido imediato comum entre si, apresentaramse como "movimentos emergentes, signos que indicam que algo acontece, que há uma processualidade em curso" (Kastrup, 2007, p. 18).

Como residente aprendiz de "cartógrafaetnógrafa", mergulhada no campo, em posição de estranhamento inevitavelmente transitória, portanto, estrangeira, senti-me pronta para o desafio de passar da "observação participante", vivida até então, para uma "participação observante", tal qual apontam Barros e Kastrup (2009 citados por Cicourel, 1980). Propus então à equipe do Ceco a construção de um espaço em que os participantes pudessem experimentar a escrita como forma de expressão.

Preocupamo-nos (residente e equipe) em compor um espaço pensado através da noção de oficina apresentada por Galletti, citado por Lopes (1996), que trata esse dispositivo como um instrumento quase sempre experimental, que não se embasa em concepção teórica rígida ou em formas pré-estabelecidas de funcionamento.
Trata-se de um dispositivo, portanto, construído essencialmente no cotidiano, pelos usuários e técnicos.

Um grande escopo de atividades e práticas pode englobar esse conceito de Oficinas, desde que elas - atividades e práticas - se desenhem em um campo entendido como clínico, no qual os instrumentos e técnicas da oficina sirvam em função de facilitar e propiciar a expressão dos sujeitos, além de assumirem caráter reabilitador, para o qual os projetos estão voltados para inserir e reinserir o sujeito na sociedade. (Galletti citado por Lopes, 1996). A proposta de oficina que surgia foi pautada em reunião de equipe, supervisão, em conversas com os frequentadores do serviço e em preceptoria de campo. A partir de então, foi divulgado o início do projeto, que desde seu início propôs-se como espaço aberto a todos. Foram, no entanto, convidados alguns frequentadores, pensados pela equipe como sujeitos que poderiam apreciar esse espaço, na medida em que traziam demandas e o desejo de expressarem-se pela escrita. 


\section{A Oficina de Palavras e "o que se passa por aqui"}

O grupo reuniu-se pela primeira vez em uma quinta-feira. O relógio marcava dez e meia da manhã. Para disparar a conversa inicial e nosso contato com a proposta de grupo que ali se formava, sugerimos a escrita de cartas, nas quais os participantes pudessem escrever qualquer coisa que desejassem. Estavam presentes dez frequentadores do Ceco e, na mediação, nos fizemos três: psicóloga residente, terapeuta ocupacional do ceco e estagiária de terapia ocupacional. Formamos uma espécie de círculo em que podíamos, todos e todas, olhar-nos nos olhos.

Sendo o Centro de Convivência e seus dispositivos espaços abertos, onde os frequentadores podem ir e vir a qualquer momento (Galletti, 2004), muitos dos presentes nesse primeiro encontro foram, vieram, retornaram ou não. Alguns permaneceram e estabeleceram profundas relações de vínculo e sentido com o que se foi tornando a Oficina de Palavras. Outros tantos foram chegando e partindo ao longo do caminho.

O encontro iniciou com cada um se apresentando. Dissemos nossos nomes e algo que gostávamos (de fazer, de comer, de ser) e em seguida nos propusemos a dizer o que esperávamos desse encontro de pessoas, que, tímidas no início, aos poucos engataram em uma conversa sobre experiências singulares com a escrita. Foi possível perceber que cada um ali experimentou diferentes contatos com os códigos da língua portuguesa, escrita, lida ou falada. A maioria das pessoas eram não alfabetizadas ou estavam em processo de alfabetização, e outras já eram mais experientes com a escrita e a leitura.

Cada subjetividade ali partiu de contatos singulares com a criação de palavras. Pessoas com muito a dizer e expressar, 
"O QUE SE PASSA POR AQUI": CARTOGRAFANDO PROCESSOS DA OFICINA DE PALAVRAS EM UM CENTRO DE CONVIVÊNCIA

mas que, por distintas razões, foram afastadas do acesso à aprendizagem da tão erudita língua portuguesa escrita. Esse fato não os privou, contudo, de escolher a palavra escrita para expressarse. Delineava-se, sob essa perspectiva, o tal "perfil" do grupo. Com as participantes que apresentam menor facilidade com a língua escrita, nós, mediadoras, nos dividimos para acompanhar o processo, emprestando nossas mãos para a escrita das palavras. As produções foram partilhadas em roda.

Codos quiseram deixar seus escritos no Ceco, combinamos que o grupo teria uma pasta para guardar as produções e um caderno para anotar ideias e impressões de cada encontro.

Desde esse primeiro momento o grupo produziu muitas reflexões, houve surgimento de poderosos afetos e abertura ao sensível. Evidenciou-se, desde esse primeiro instante, que as Oficinas nos Cecos são o grande desafio colocado aos trabalhadores, pois convocam, constantemente, a "recriação de si e das próprias experiências" (Galletti, 2004, p. 59)

O encontro nos apresentou, ainda, aquilo que fez o "Grupo de Escrita" tornar-se a "Oficina de Palavras" - o maior desafio, e também uma das maiores potencialidades e belezas do grupo: em sua grande parte, as pessoas que o buscavam e o compunham eram essas que experimentam outras relações com a linguagem. Pessoas que não necessariamente leem e escrevem, mas que se atrevem a desejá-los.

\section{Inventando a nossa linguagem: 0 caminhar da Oficina de Palavras}

Desse primeiro momento, transcorreram-se encontros semanais.
A cada encontro os participantes da oficina foram inventando suas próprias 
"pontes de linguagem" (Rolnik, 1989), encontrando meios de dar passagem à suas tantas intensidades em busca de expressão. Clarice ${ }^{3}$, por exemplo, foi experimentando até entender a preferência por trabalhar com colagens e histórias criadas a partir delas. Retomo uma cena viva em minha memória: Clarice com um cartaz autoral, colagens e frases para a marcha do Dia da Luta Antimanicomial. Agarrava-se ao cartaz com força e com atitudes próprias de sua natureza altamente sociável, puxava assunto com qualquer pessoa que the chamasse - ou the desse - atenção. Uma senhora que lê atentamente o cartaz de Clarice diz: "esse cartaz representa tudo que penso, está lindo". Em um ímpeto, Clarice quis presentear a senhora com a sua produção, e então recebeu a resposta: "mas não pode ficar guardado na minha casa, tem que ficar exposto, pra todo mundo ver". Clarice então leva o cartaz de volta ao Ceco. Desmonta-o, para então remontá-lo. Decide transformar em livro.

${ }^{3}$ Os nomes dos participantes do grupo foram substituídos por nomes fictícios.
Se Clarice trabalha em seu livro e pede nossas mãos emprestadas para fluir suas ideias, Lygia, por sua vez, tem grande apreço pela escrita com suas próprias mãos. Pede ajuda na formação das palavras e precisa que ditemos às vezes letra por letra. Contudo, algumas palavras ela sabe de memória e coração. Um tempo: hoje. E um verbo: quero.

Tal qual Clarice e Lygia, todos os participantes da Oficina encontraram meios muito singulares de expressar as intensidades do existir. A atitude de abertura ao movimento do grupo - e ao do que dele surgiu - fez entender que foi o fato de "estar junto enquanto fazíamos" que possibilitou, aos poucos, a criação de uma linguagem comum - a linguagem da oficina - mesmo que nem todos estivessem no mesmo registro ou ritmo de linguagem. Mais do que fazer junto, desde o primeiro instante esteve presente 0 exercício do compartilhamento de experiências (Galletti,2004). 
A pasta de produções ficava cada vez mais cheia daquilo que cada um criava. Nós, mediadoras, sempre impactadas com a riqueza, profundidade e espontaneidade com que surgiam as palavras, ao mesmo tempo nos víamos angustiadas mediante questionamentos e problematizações suscitadas pelos processos do grupo. Que destino teriam suas produções?

As reflexões suscitadas pela Oficina remetem à regra do cartógrafo, descrita por Rolnik (1989) como "regra de ouro":

O cartógrafo sabe que é sempre em nome da vida, e de sua defesa, que se inventam estratégias, por mais estapafúrdias. Ele nunca esquece que há um limite do quanto se suporta, a cada momento, a intimidade com o finito ilimitado, base de seu critério: um limite de tolerância para a desorientação e a reorientação dos afetos, um 'limiar de desterritorialização' (Rolnik, 1989, p. 4).

Foi primordial, nesse processo aqui recriado, poder entender o quanto o grupo suportava mudanças ou não, à medida que avançava, o que permitiu uma espécie de feeling que variava em função da singularidade de cada situação, traduzindo-se em uma "regra de delicadeza para com a vida" (Rolnik, 1989, p. 4). As respostas para nossas perguntas (e também para perguntas novas) surgiam conforme o limiar de desterritorialização do grupo se transformava.

Em um encontro definitivo, uma das participantes, que aqui chamaremos de Hilda, sugere construirmos um "jornalzinho" com as produções da Oficina. Diz que "não dá para ficar parado, guardado na pasta", e sugere um nome para o projeto: “O que se passa por aqui". Chegamos então à proposta de confeccionar um fanzine com esse título. O grupo todo, atento e participativo, começa a revisitar os trabalhos de cada um, decidindo o que daquilo que foi feito queria mostrar, pensando de que forma iríamos começar a contar aos outros. 


\section{Ampliando o limiar de}

\section{desterritorialização: a construção do}

\section{fanzine, os passeios e a ida à Biblioteca}

\section{Municipal}

A experimentação estética de escrever o fanzine proporcionou a possibilidade de aventurar-nos na fronteira que Lima (2006) aborda ao tratar das intervenções clínicas em interface com as produções estéticas. A autora descreve uma "linha fronteiriça na qual a vida disputa com a doença, a miséria, a morte" (Lima, 2006, p. 318).

A vivência de estados clínicos proporcionados pela criação artística e experiências estéticas é observada como produtora de um poderoso efeito para quem a experimenta, (Lima ,2006). Nesse contato com a criação, o sujeito vai além de expor a si mesmo e ao seu sofrimento: ele realiza um fato de cultura.

O "fato de cultura" nomeado "O que se passa por aqui", quando pronto, foi levado pelo grupo para impressão em gráfica próxima ao Centro de Convivência.

O trajeto de cinco minutos tornou-se um passeio ao longo da caminhada, cada folha de outono era celebrada, cada animal que passava merecia alguns minutos de atenção e cada piada gerava gargalhada. Manoel, atento e intenso aos acontecimentos revela: "vou escrever sobre o passeio até a gráfica". 
Depois desse dia, o registro no diário de campo trazia a fala de Manoel transcrita, seguida de uma observação: "às vezes parece que esse grupo produz vida o tempo todo". De fato, podemos observar a produção do fanzine e o contato com a criação de palavras como fatores que provocam um enriquecimento das vidas implicadas nesse processo, "tomando a vida, e não a arte, como critério" (Lima, 2006, p. 326).

A apropriação de um modo de expressão dominante (a escrita) por parte desse grupo de pessoas permitiu o atravessamento da linha divisória que separa esses corpos da produção cultural. Existe, portanto, um aumento da cidadania cultural, ponto que Lima (2006) enxerga como extremamente relevante no tocante à produção da vida e à ampliação de suas possibilidades.

Desterritorializados, à medida que construíamos novos sentidos, também conseguíamos ampliar nossos espaços de circulação pela cidade, enquanto coletivo. $\mathrm{O}$ grupo que antes se mostrava receoso e desmotivado com atividades externas criou, tal qual descrito em registro no diário de campo, "uma paixão pelas saídas".

Um passeio vislumbrado desde o início do ano: a Biblioteca Municipal. Lygia revelou, na poesia que compõe o fanzine, que dentre seus tantos sonhos estava o de conhecer "a biblioteca e o mundo". "Eu tenho vontade, amor" - escreveu em uma de nossas agitadas quintas-feiras

O funcionário que nos recebeu na biblioteca preparou-se para isso, contou a história da biblioteca e leu um livro para nós. Conhecemos o setor de braile da biblioteca, sentimos os livros, exploramos outras formas de ler.

Nas paredes do prédio, uma exposição chamada "Livro do Artista" - uma série de criações literárias que fugiam do formato convencional. Mais uma vez o grupo experimentou a ampliação de sua cidadania cultural ao reconhecer, em algumas das obras expostas, semelhanças com nosso fanzine. Saímos, inclusive, com a ideia de colocar o fanzine junto às obras da exposição. Contudo, no encontro que precedeu a emocionante ida à biblioteca, ao conversarmos coletivamente sobre a proposta, e como 
ela poderia ser articulada, Lygia lembra a nós, mediadoras, mais uma vez, do exercício constante da "regra de ouro" da cartografia, postulada por Rolnik (1989). Lygia opõe-se ao fanzine exposto na biblioteca, suas falas nos impactam: "vão jogar fora, tacar fogo, rasgar" ou "não vão ligar". Estávamos ali esbarrando mais uma vez nos limites da desterritorialização, e o quanto dela se suporta. Se não estávamos prontos para

\section{Considerações finais}

A experiência de acompanhar e intervir no processo de criação e construção da Oficina de Palavras redimensionou e transformou ideias formatadas de pensar - cuidado, a produção de vida e a Reabilitação Psicossocial. Proporcionou o encontro com diferentes abordagens teóricas e nos fez chegar à cartografia, como tentativa de nomear e acompanhar os processos disparados em nós, "criadores de palavras".

Sendo a cartografia um espaço, como postulado por Rolnik (1989), de o passo de expor o fanzine, por outro lado, ganhamos novos elementos para a composição de nossos encontros: descobrimos que, além da criação de palavras, apreciávamos a leitura de livros, feita coletivamente. A última anotação em diário de campo tentou definir a poesia de palavras em toda sua metalinguagem: "sujeitos que falam sobre poesia se atrevem a fazer poesia, enquanto são poesia em ato."

emergência de intensidades sem nome e germinação de novas ideias e novas línguas, e pensando a Oficina de Palavras como uma grande cartografia produzida constante e coletivamente no decorrer dos encontros do grupo, atrevo-me a concluir que esse processo configura algo próximo ao que é denominado "uma literatura menor".

Uma literatura menor não é a de uma língua menor, mas antes, a que uma minoria faz em uma língua maior. (...) A segunda característica das 
literaturas menores é que, nelas, tudo é político. (...) A terceira característica é que tudo adquire um valor coletivo. (...) E se o escritor está à margem ou afastado de sua frágil comunidade, essa situação o coloca ainda mais em condição de exprimir uma outra comunidade potencial, de forjar os meios de uma outra consciência e de uma outra sensibilidade. (Deleuze e Guattari, 1977, citado por Lima, 2006, p. 25)

A Oficina de Palavras entendida como a constituição de territórios existenciais e construção da realidade pôde existir em um Centro de Convivência não à toa, e sim a partir de um espaço privilegiado para pensar ações com esses fins, na medida em que busca a criação de modos de inclusão de pessoas em situação de exclusão, em articulação constante com a vida cotidiana e a cultura. Como apontam Ferigato, Carvalho e Teixeira (2016, p. 83), procuram criar:

novos modos de sociabilidade, ou ainda fabricar formas de sociabilidade alternativas, das quais todos nós estamos excluídos, na medida em que, em um contexto neoliberal, todos nós somos privados, em alguma medida, de viver um modo de convivência que valorize a ação coletiva pelo projeto neoliberal de sociedade.

Em um contexto político no qual o Estado brasileiro é governado por forças "que seguem uma agenda conservadora, ferindo e restringindo direitos sociais historicamente conquistados pela via do dispositivo do ajuste fiscal, antiga bandeira neoliberal" (Yasui, 2009, p. 225), direitos e conquistas no que se refere ao modelo de Atenção Psicossocial estão sob ameaça, evidenciando um forte desinvestimento das políticas públicas.

“Os valores implícitos na política do SUS e da Atenção Psicossocial como a solidariedade, compartilhamento, participação, são subsumidos pelos valores reinantes no mercado: o individualismo, a competição, o lucro" (Yasui, 2009, p. 212). Tais valores são apostados em sua radicalidade no funcionamento dos Cecos, serviços que, no atual contexto aqui explicitado, tornam-se pontos ainda mais frágeis da Rede de Atenção, para os quais não 
"O QUE SE PASSA POR AQUI": CARTOGRAFANDO PROCESSOS DA OFICINA DE PALAVRAS EM UM CENTRO DE CONVIVÊNCIA

existem políticas públicas oficiais de financiamento e implementação, sendo equipamentos investidos em poucos municípios brasileiros.

Nesse sentido, talvez seja possível pensar a resistência dos Centros de Convivência em continuarem existindo em cenário tão hostil como uma possibilidade de construção daquilo que denomina como uma "Atenção Psicossocial menor", que consiste em "ousar mais, correr riscos, investir em agenciamentos coletivos, em múltiplas dimensões. (...) Fazer a política como celebração cotidiana da potência da vida e fazer da vida uma obra de arte" (Yasui, 2019, p. 229).
Em oposição ao medo e à violência, bem como à produção de indivíduos considerados "desneces-sários" para a manutenção da lógica neoliberal, (Ferigato et al, 2016), existe na proposta dos Centros de Convivência, e nos acontecimentos de cotidiano - tal qual a Oficina de Palavras - o resgate da capacidade de iniciativa política e da cidadania dos diferentes grupos sociais que por ali passam. A aposta feita é na reestruturação, a partir do plano micropolítico, menor, dos laços sociais enfraquecidos e na produção de redes afetivas que produzem saúde e vida.

\section{Referências}

Aleixo, J. M. P. (2013). Centros de Convivência: Experimentando outras formas de trabalho e gestão. In Pádua, E.M.M.; Feriotti, M.L. (Orgs.). Terapia Ocupacional e Complexidade - práticas multidimensionais. Curitiba: CRV., pp. 127-142

Aleixo, J. M. P. (2016). Centro de convivência e Atenção Psicossocial: invenção e produção de encontros no território da diversidade. Tese de doutorado, 
"O QUE SE PASSA POR AQUI": CARTOGRAFANDO PROCESSOS DA OFICINA DE PALAVRAS EM UM CENTRO DE CONVIVÊNCIA

Faculdade de Ciências e Letras de Assis, Universidade Estadual Paulista, Assis, SP, Brasil.

Brasil, Portaria n 3088, de dezembro de 2011. Rede de Atenção Psicossocial. Ministérios da Saúde. Gabinete do Ministro. 2011.

Barros, L.P \& Kastrup, V. (2015). Cartografar é acompanhar processos. In Passos, Eduardo; Kastrup, Virgínia \& Escóssia, Liliana. Pistas do método da cartografia. Pesquisa-intervenção e produção de subjetividade. Porto Alegre: Sulina.

Deleuze, G., \& Guatari, F. (1995). Mil Platôs. Vol. 1. Rio de Janeiro, RJ: Editora34 Letras.

Escóssia, L., Kastrup, V. \& Passos, E. (2015). Pistas do Método da Cartografia: Pesquisa-intervenção e produção de subjetividade. Porto Alegre, RS: Editora Sulina.

Ferigato, S. H. (2013). Cartografia dos Centros de Convivência em Campinas: Produzindo redes de encontros. Tese de doutorado, Faculdade de Ciências Médicas, Universidade Estadual de Campinas, Campinas, SP, Brasil.

Ferigato, S. H.; Carvalho, S. R. \& Teixeira, R. R. (2016). Os centros de convivência: dispositivos híbridos para a produção de redes que extrapolam as fronteiras sanitárias. Cad. Bras. Saúde Ment., Florianópolis., 8 (20), 80-103. Acessos em 21 dez. 2018.

Galletti, M.C. (2004). Oficina em Saúde Mental: Instrumento Terapêutico ou Intercessor Clínico? Goiânia, GO: Editora da Universidade Católica de Goiás. Kastrup, V. (2007). O funcionamento da atenção no trabalho do cartógrafo. Psicol. Soc., Porto Alegre, 19 (1), 15-22. Disponível em:http://dx.doi.org/10.1590/S0102-71822007000100003. Acesso em: 10 dez. 2018. 
"O QUE SE PASSA POR AQUI": CARTOGRAFANDO PROCESSOS DA OFICINA DE PALAVRAS EM UM CENTRO DE CONVIVÊNCIA

Lima, E. M. F. A. (2006). Por uma arte menor: ressonâncias entre arte, clínica e loucura na contemporaneidade. Interface (Botucatu), Botucatu, 10 (20), 317329. Disponível em: http://dx.doi.org/10.1590/S1414-32832006000200004. Acesso em: 17 fev. 2019.

Prefeitura do Município de São Paulo PMSP (1992). Programa de Saúde Mental. Normatização das Ações nos Centros de Convivência e Cooperativas Municipais, São Paulo.

Rolnik, S. (1989). Cartografia ou de como pensar com o corpo vibrátil. Trechos de Suely Rolnik: Cartografia sentimental, transformações contemporâneas do desejo. São Paulo, SP. Editora Estação Liberdade.

Yasui, S. (2019). Aposta em uma atenção psicossocial menor. In Emerich, Bruno Ferreira \& Onoko-Campos, Rosana Teresa. SaúdeLoucura 10. Tessituras da clínica - Itinerários da reforma psiquiátrica. São Paulo: Hucitec.

Recebido em: 08/08/2020 Aprovado em: 15/12/2020 